\title{
Lucha Libre: Visualising behind the mask
}

\author{
Javier Pereda \\ Southampton Solent University, TrinkerMedia \\ East Park Terrace, Southampton UK SO14 OYN \\ trinker@hotmail.co.uk \\ javier.pereda@solent.ac.uk
}

\begin{abstract}
Lucha Libre has played an important role in Mexican culture since the late 1950s. At its early stage, wrestling from the United States and the French "Catch as Catch Can" blended within popular Mexican culture absorbing its social, political and mythical idiosyncrasy evolving later into what it would be known as Lucha Libre. This sport has become famous mainly due to its masked wrestlers which embed their family traditions, beliefs and fears into the design of their masks, allowing them to transform a regular person into a fearless character.The objective of this project is to analyse and present how the visual elements within the masks are created and how they evolve through time. Utilising several visual communication methods I have been able to explore the ideas and processes behind the characters creation and its evolution inside the Lucha Libre media. This has been done through the implementation of diverse technologies which enables any user to be submerged into the world of Lucha Libre and witness that experience. Through the next interactive exhibitions, this project offers a mixture of visualisation, technology and social theory, looking to understand the anthropological complexity behind the design of the masks inside the Lucha Libre world.
\end{abstract}

Lucha Libre, Wrestling Masks, Graphic Design, Anthropology, Multimedia, Interfaces, Data Visualization, Flash Technologies, Actionscript 3.0, Moowheel, Mexico

\section{INTRODUCTION}

Lucha Libre is an event in which the worlds of sport and theatre meet, generating a new concept where two or more challengers fight in a blend of Greekroman wrestling, acrobatics and other combined martial arts. The main essence of Lucha Libre borns from the evolution from Wrestling. However, it differs from it because Lucha Libre have had social repercussions and is deeply impregnated with local cultural elements.

The born of masked wrestlers took place in the United States from a Circus side act. The performers started to wear masks as an appealing way to attract the audience. In1933 the first formal wrestling match took place in Mexico with the foundation of the first company dedicated only to Wrestling (Grobet, 2006). This match was hosted in what is now known as the Arena Mexico, giving birth to the Lucha Libre concept, in which wrestling started adopting the Mexican culture impregnated in the use of masks and theatrical fights.

The functionalism inside Lucha Libre is built with extreme basic information. A simple fight between characters that represent good and evil, which in Lucha Libre is known as Tecnicos (Faces) versus Rudos (Heels). This builds the meta-narrative of every event and every character involved, attempting to be pluralistic in order to reach the masses and enable wrestlers to present their characteristics to people as truth. Based on the meta-narrative presented by Lucha Libre, the audience truly believes that the opponents genuinely hate each other, generating an hyperreal response from the audience full of authentic emotions.

As a Mexican graphic designer, my work is imbued with a mixture of cultures, colours and ideologies. For this material compilation, the work itself is a combination of art and technology which encompasses the identity of my culture and Lucha Libre. The idea behind is to present Lucha Libre, giving emphasis to the design of the masks. There is an immense cult behind Mexican wrestling notably in Japan, the United States and, of course, Mexico. My work attempts to introduce the audience to the hidden world behind the wrestling mask and furthermore, to open the knowledge regarding the Mexican wrestling world.

This exhibition is meant to interact with the audience so they are able to become involved with the characters and the sensations invoked by their designs. Its interactive material, combined with the 
printed material converges together creating an integral and multi-skilled project.

\section{DATA VISUALISATION}

Through visual representations of data, we are able to communicate any kind of information to any audience. Data visualisation is directly related to information graphics, information visualisation, scientific visualisation and statical analysis graphics.

The information provided is presented in an abstract form and includes values, variables and internal information that does not link directly in the first line of thought. Data visualisation will study this representation of data and produce an accessible approach to this information (Friendly, 2001).

\subsection{Data Visualisation 01: Bets and Teams}

Poster $13.2 \mathrm{~cm}$ by $19.2 \mathrm{~cm}$.

In Lucha Libre there are special matches in which wrestlers gamble their mask against other mask, hair or even careers. These are processes in which the managers, promoters and story line writers get together to promote the career of a specific wrestler. As part of this promotion or marketing strategy, the wrestlers will create an alliance with other wrestlers and build teams that could be related with the visual characteristics, narrative of their character or even built up an idea of bad blood in between wrestlers. Some of them have the opportunity to manage their own storyline and decide their path through the Lucha Libre narrative (Bischoff, 2006). In any of these cases, the mask play a fundamental role in impersonation of the character, and to bet it in a match, provokes some of the biggest sport events in Mexico. Through these visual characteristics the audience identifies themselves with the performer. At the same time some wrestlers create relationships based on the visual elements and concepts that build the character.

This data visualisation poster displays these complex relationships between wrestlers and marketing strategies, depicting who has won against who. The visualisation presents a circular pattern in which the wrestlers are arranged through the perimeter of the inner circle. The poster can be placed facing up to be in Spanish, and upside down to be in English. On the left side we can appreciate the main rudos (heels), and on the right side the tecnicos (faces). Inside the main wheel, the relationships of the matches are presented with a colour line, depending on the character, along with the year the event took place.
The external circle presents the teams in which these wrestlers have been joining forces with. Several Lucha Libre teams are formed through family bonds like in the case of Los Villanos (The Villains) or Los Brazos (The Arms). Others like Los Cadetes del Espacio (The Space Cadets), teamed up based on the "astronomical" symbols and characteristics of their costumes.

Through this data visualisation the visual characteristics of the wrestlers and their relationships becomes evident due to the visual gathering. The meta-narrative of Lucha Libre is presented within the circle. Following traditional design principles in shape and visual psychology (Katz, 1945), in which the arrangement of the negative, usually pointing to the left, the Rudos (heels) are mounted in this side of the circle, while the positive, always moving forward are placed on the right side, which is the case of the Tecnicos (faces). The visual origin is located at the centre of the visual information, from where the audience can proceed to segregate the two main groups within the meta-narrative of Lucha Libre.

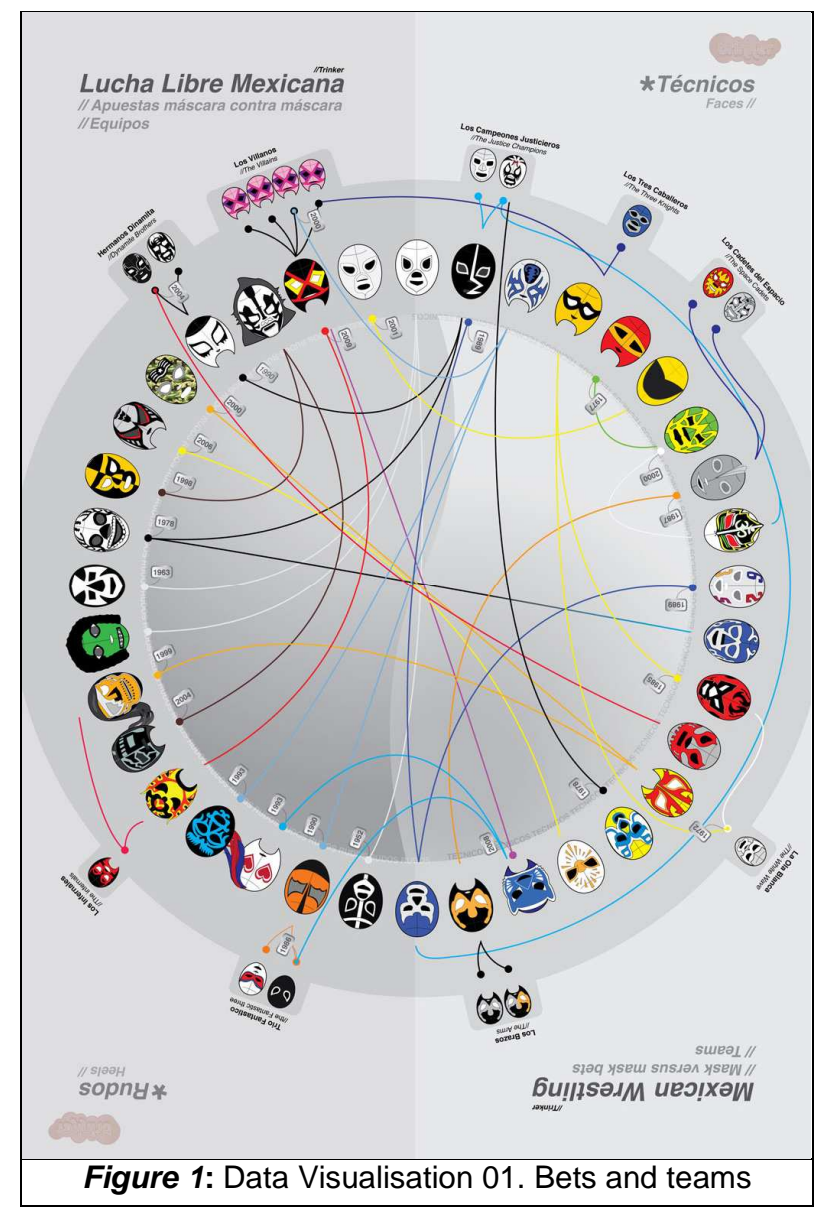

The visualisation presents that in few cases the faces will make bets against the same side of the their circle. This is a response from the 
promotional story-line of the wrestler. It is more common for a Face to become more popular and generate more monetary revenue (Bischoff, 2006), and these lines answer to the progression of the wrestler through the rosters.

\subsection{Data Visualisation 02: Social Network Analysis of Bets}

Poster $200 \mathrm{~cm}$ by $100 \mathrm{~cm}$.

This other poster (Figure 8) uses over 120 wrestlers on the database. The information displayed covers the wrestlers who lost the masks, hair or beard and who did they lost it against. The information is displayed like fractals in which the winning character behaves as a main cell from where the rest of the elements expand, representing the defeated, making an exponential division for each wrestler. The poster contains a grid to allow the viewer to locate faster a desired wrestler and find its co-ordinates.

The methodology for this Visualisation was based on centrality mapping. This means that it focuses on the number of direct connections that each node has, analysing the nodes that contain the biggest network reach and boundary players to increase the amount of peripheral players. This augment the size of the visual, since they become in their turn the central node.

The first step was to pre-visualise which nodes were the longest and had more network reach. In a sense I knew (as it has been part of my research) which wrestlers had more reach, taking in considerations issues like: family members, championships and time in the industry. For this pre-visualisation I used a mind map alike technique, which objective was to clarify and disentangle the observed relationships. After sketching a rough approximation of the information to be displayed, the next step was to define the main iconography system.

Based on the display elements recommended by Edward Tufte (1942:13), to be able to communicate with clarity, precision and efficiency, the visualisation was required to build a system of visual elements to encapsulate the information. This representational information included:

- Win / loose.

- Typology of bet: mask, hair and beard.

- Central node

- Encapsulation
The result of these elements was resolved as follows:

A main circle is designed to contain the main elements. It contains a ring on the outside that will utilise a representative colour for the wrestler and the inner circle is always the same colour. The colour of the ring then will be used as the connection line for the vectors (Figure 2).

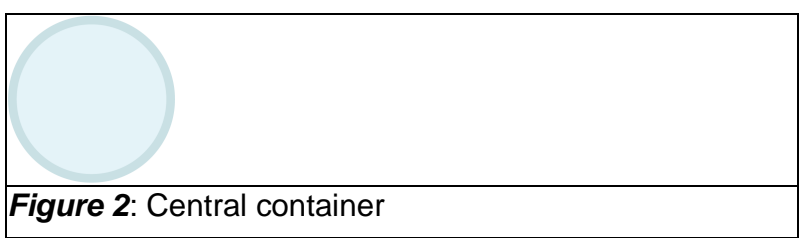

Since not all the characters will behave as central nodes, I placed them within a dark magenta circle. This circle is used mainly for all the loosing wrestlers (Figure 3).

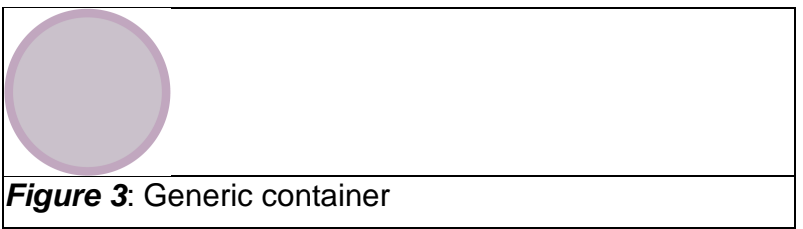

After defining the circles the representation of the mask and their name in grey was placed underneath it (Figure 4).

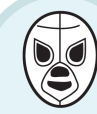

Figure 4: Container with data

Since I wanted to keep focus on the central nodes, I developed a template mask that is used on all the non-central (loosing) nodes (Figure 5).

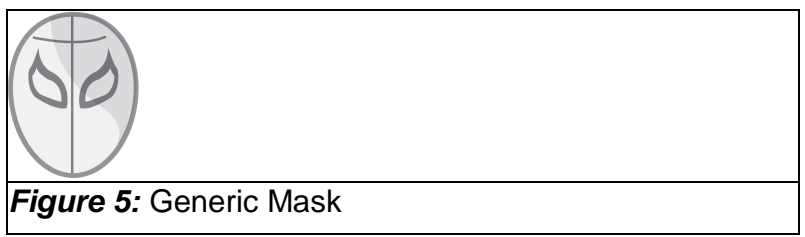

The mask, beard or hair icons can be placed on a big scale on the centre of the circle to represent the character. If the icon is placed on the ring of the node, it represents the type of bet item that took place on the event. The bet item icon will be placed on the losing node (Figure 6). 


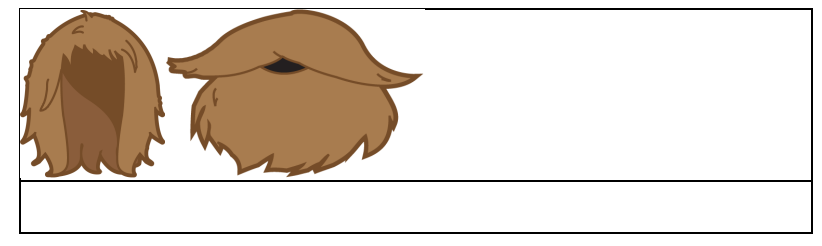

This visualisation presents the social network of matches and the transition of wrestlers through time. The wrestlers who are visualised centrally, seemed to be related to a shorter period of popularity in which the wrestler just presented a few chances to pursue his popularity. Some of the characters present a longer line in which translates through the canvas, this indicates a longer period of popularity and bigger chances to pursue these bets and promotions. Few of the characters present less winnings but still manage to translate through other circles, I will argue that this is due to the short time inside the sport thus an increasing popularity. These jumps into other networks, present transitions through time and through popularity in many cases within the visualisation.
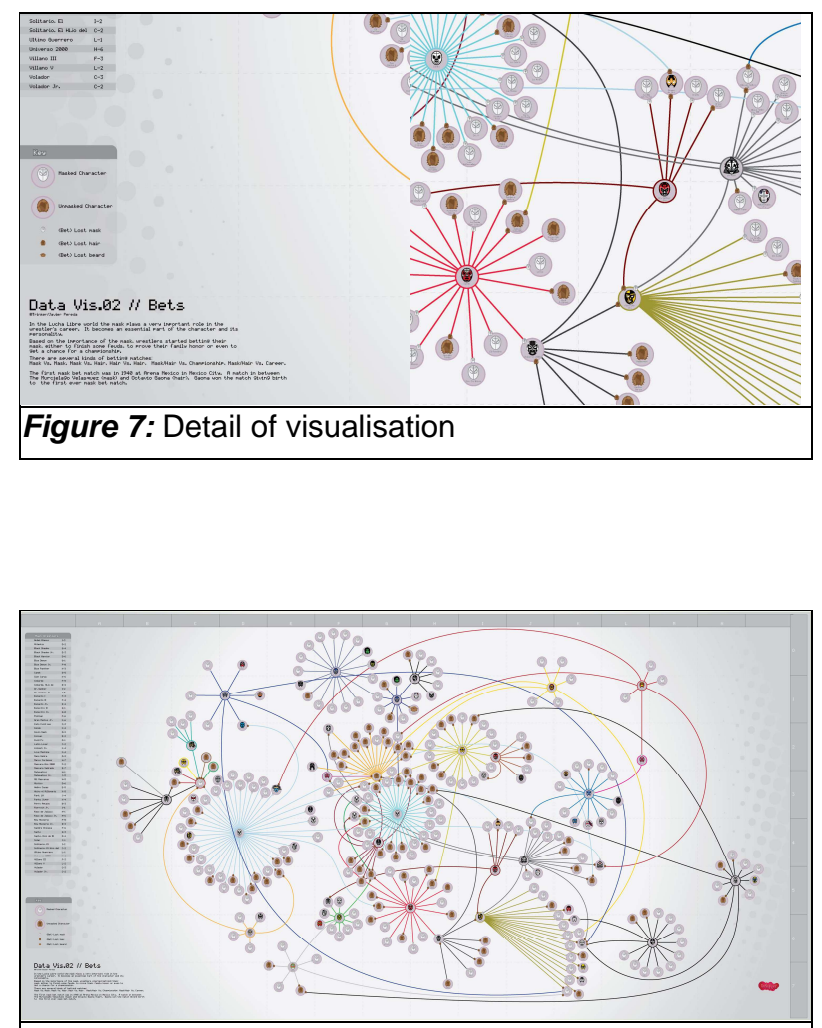

Figure 8: Data Visualisation 02. Social Networks of Bets

\subsection{Data Visualisation 03. Bets Moowheel}

Interactive Interface
This is an interactive interface developed with Moowheel (Gross, 2008), a JavaScript library licensed under an MIT-style license.

Using the output of the last data visualisation poster, I developed this interface allowing the user to interact with the information. The user can click the name of the wrestler, redirecting him to the a database in LuchaWiki (Fernandez, 2011), in which the personal biography of the wrestler will be displayed. The main wrestlers have an icon next to the name, in order to recognise them faster.

With the help of the Moowheel visualisation, the data presented was able to be rearranged through the space. Instead of centralising it to a specific character, every character has now the same level of hierarchy. This transforms the visual result of the bet matches.

Through this visualisation we can appreciate that the wheel is mainly connecting to the same side where the original node (wrestler) starts. This result can be linked to the popularity and progression.

The main visual result is in the shape of a fan. Starting from a single node and expanding to the subsequent nodes, the wrestler presents a large amount of wins. When the line jumps into a different side of the wheel, it can be interpreted as the time succeeding within the industry. As time progresses other wrestlers start appearing, but even though they manage to win some important matches, most of them are not capable of maintaining that popularity through time and therefore to jump to the other side of the wheel.

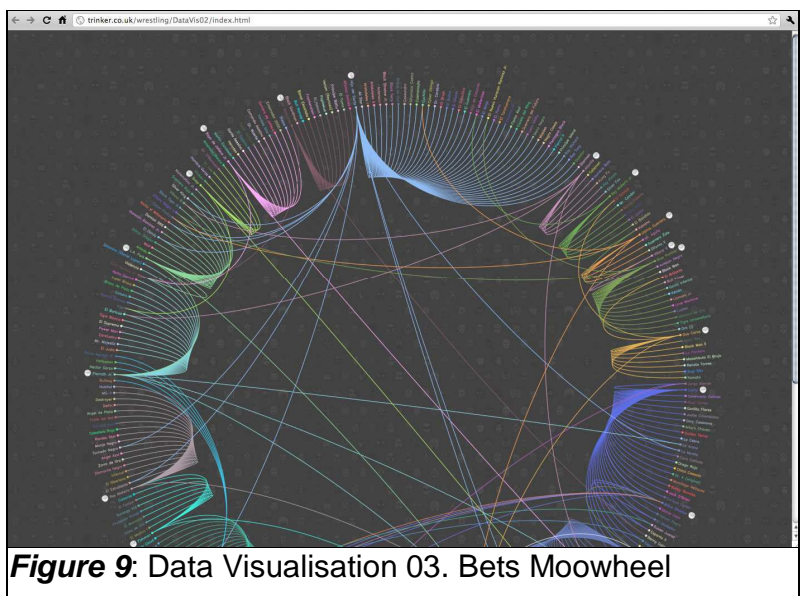

\section{WRESTLING DIGITAL ART, TRINKER MASKCAM}

Interactive Interface

Based on the visualisation developed by Matt Booth (Booth, 2009), this interface uses any kind of video input. This is recognised by the interface and 
then translated into a mosaic build from over 160 mask icons which act like pixels to generate a brand new image and it can be modified to increase the size of the mosaics. This interface was developed as a Flash application and the output can be projected on a wall, can be used as a wallpaper or it can be displayed in any traditional monitor.

The interface is designed to work with any webcam and a computer that allows Flash to access the camera. The concept of this interface is to see how people react when they are behind a visual screen which hides their identity. The same way wrestlers present themselves behind of a veil, this interface emulates a digital veil in which the user can experiment an behave differently.

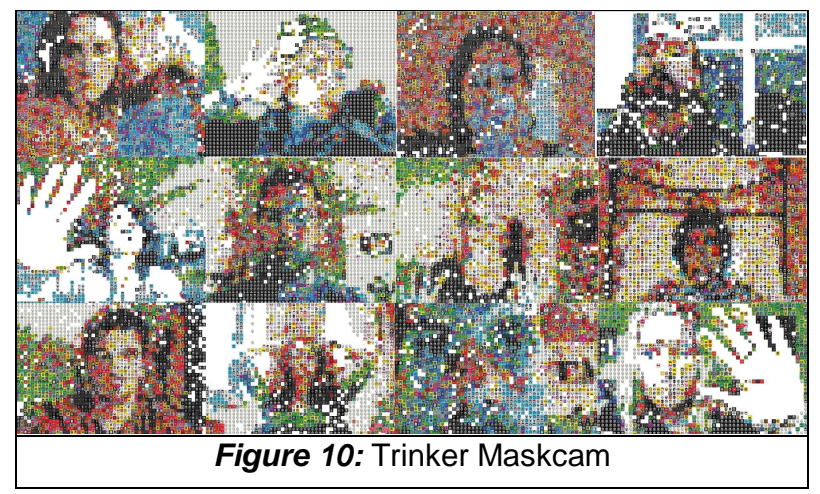

\section{INTERACTIVE DIDACTIC MEDIA, THE MASK SPINNER}

Interactive Interface

Originally this interface was developed to define the main styles on wrestling masks. After defining them, a basic image identity was developed for each one of the wrestlers presented.

The interface presents a "template" wrestler which appears with his tights on grey and without any mask. I have chosen 20 different masks. These masks have been separated into the three main styles. The traditional closed design counts with seven masks. The second style is the open mouth style having three masks in this category. The last one is the Japanese style, in which the nose and the mouth are uncovered. This category counts with two masks.

The masks spin in a circular way around the wrestler. It spins by using the left and right control keys. There are three main rollover icons on the bottom defining the three main styles of the masks, when they are hovered, the mask spins to the front of the wrestler showing the user the style. When a mask is clicked, the masks spin until the mask that was clicked is placed in front of the face of the wrestler and the background with the visual mood of the wrestler is loaded on the background. In addition, the basic colour scheme is loaded into the main "template" character.

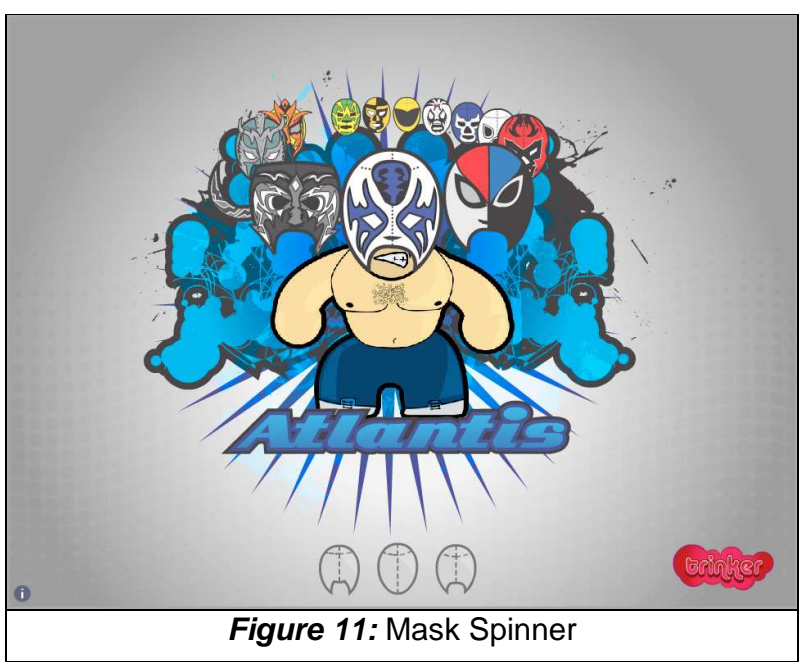

\section{CONCLUSION}

The necessity to visualise the concepts of how the Lucha Libre world works enabled me to explore deeper the methods and technologies of visual communication. These techniques can be applied to help understanding the interaction impact in between performer and audience, which at the same time can be interpreted as the one between user and interface.

Trying to understand how media and the elements inside Lucha Libre connect in between each other, I have attempted to illustrate the typology of these masks with the Mask Spinner (Figure 11) and emulate the psychological response of the mask user with the MaskCam (Figure 10). The use of visual experimentation and the application of essential visual communication methodologies emulates and imitates some process in which the wrestling masks and characters are created. They all need to communicate a message.

The requirement to visualise quantitative size changes, direction and descriptive elements can be supported by graphical visualisation (Tufte, 1942). My final intention, was to introduce an audience into this hidden world through these interfaces and visualisations with the purpose of exploring how do we communicate visually and how do we interact with each others as users and community members. 


\section{REFERENCES}

BISCHOFF, E., AND ROBERTS, JEREMY. 2006. Controversy Creates Cash, New York, World Wrestling Entertainment Books.

BOOTH, M. 2009. Mr. Booth [Online]. Mr. Booth. Available: http://mrbooth.co.uk/ [Accessed June 2010].

Fernandez, A. (2004). Santo, el Enmascarado de Plata: mito y realidad de un heroe moderno. Mexico City, Colegio de Michoacan - Conaculta.

FERNANDEZ, J. 2011. LuchaWiki [Online]. Lucha Wiki.

Available: http://luchawiki.com/index.php?title=Main Page (4 March 2011).
FRIENDLY, M. 2001. Visualizing categorical data Cary, N.C., Sas Institute.

GROBET, L. 2006. Espectacular de lucha libre, Mexico City, Trilce.

GROSS, J. 2008. Moowheel [Online]. Unweldy Studios.

Available: http://labs.unwieldy.net/moowheel/ (June 2009).

KATZ, D. 1945. Psicologia de la forma, Madrid, Espasa-Calpe.

TUFTE, E. 1942. The visual display of quantitative information, Cheshire, Graphics Press.

Vilchis, L. (2002). Metodologia del Diseño: Fundamentos Teoricos. Mexico, D.F., UNAM.

Vilchis, L. (1999). Diseño. Universo de Conocimeinto. Mexico, D.F., UNAM. 